\title{
PERANAN DAN SUMBANGAN ORANG CINA DI HOIAN, VIETNAM PADA ABAD KE-17 HINGGA ABAD KE-18
}

\author{
Ong Kui Hua
}

\begin{abstract}
After the fall of the Ming Dynasty in 1644, many palace officials and army officers of the Ming Dynasty migrated from China to Hoian in central Vietnam. Many of them had left because of their refusal to shift their loyalty to the Qing Dynasty government. These Chinese who migrated from southern China to Hoian also comprised of traders, scholars and artisans. They originated from southern China such as Guangdong, Fujian, Chaozhou and Hainan. This paper discusses the role and contribution of the Chinese in southern Vietnam's political, economic and social development in the port city of Hoian during the 17th to 18th centuries. It also examines the relationship between the Chinese and the locals which created a hybrid community called the Minh Huong community in Hoian. Furthermore, the article includes discussion on the efforts of the Chinese in preserving and maintaining their culture in Hoian. This research is important in three aspects. Firstly, there has not been any specific research about the role and contribution of the Chinese people in Hoian particularly from the 17th to 18th centuries. Secondly, this research is significant in that it explains how the relationship between the Chinese and the Nguyen government in southern Vietnam and that between the Chinese and the local community had helped them to succeed politically, economically and socially. Thirdly, this research discusses the efforts of the Chinese people to preserve their identity and culture in Hoian. This research opens a new dimension in the history of the Chinese people in Hoian, specifically, and in Vietnam, generally.
\end{abstract}

\section{Pengenalan}

Penghijrahan orang Cina ke selatan Vietnam dapat dikesan sejak Dinasti Han apabila Maharaja Han Wu Ti (140SM - 87SM) menghantar Jeneral Lu Po-te untuk menakluki Nan Yueh (Vietnam atau Nam-Viet) pada tahun 111BC. ${ }^{1}$ Akibatnya, Nam-Viet menjadi sebahagian daripada empayar China sehingga tahun 938M. ${ }^{2}$ Sejak daripada waktu itu, orang Cina mula berhijrah ke Vietnam setiap kali ada pergolakan politik di China. ${ }^{3}$

Menurut Hai Wai Ji Shi yang ditulis oleh Da Shan, sepanjang abad ke-16, sudah terdapat pedagang Cina datang dan tinggal di selatan Vietnam dengan menaiki perahu kayu ${ }^{4}$ akibat daripada ketidakstabilan politik di China terutamanya selepas beberapa sekatan dikenakan pada penganut agama Katholik di China. ${ }^{5}$ Kedatangan orang Cina di selatan Vietnam telah diterima oleh Gabenor Nguyen Hoang yang memerintah Thuan Hoa di tengah Vietnam pada tahun 1558.

Selepas kejatuhan Dinasti Ming pada tahun 1644, ramai pegawai istana dan tentera Dinasti Ming melarikan diri dan berhijrah dari China ke Hoian, Vietnam kerana enggan memberi taat setia kepada kerajaan Dinasti Qing. ${ }^{6}$ Selain itu, orang Cina yang berhijrah dari selatan China ke Hoian juga terdiri daripada pedagang, cendekiawan dan artisan. Mereka berasal dari kawasan selatan China iaitu Quang Dong, Phuc Kien, Trieu Chau, Hai Nam, He dan Chiet Giang. ${ }^{7}$

Penulisan ini membincangkan peranan dan sumbangan orang Cina dalam bidang politik, ekonomi dan sosial di Hoian, Vietnam pada abad ke-17 hingga abad ke-18. Penulisan ini juga mengkaji hubungan antara orang Cina dengan masyarakat tempatan dan bagaimana hubungan tersebut membantu mewujudkan komuniti kacukan iaitu komuniti 
Ming Huong di Hoian. Selain itu, penulisan ini juga membincang usaha orang Cina dalam memelihara dan mengekalkan kebudayaan mereka di Hoian.

Berdasarkan kajian-kajian yang sedia ada, hampir kesemuanya membincangkan komuniti Cina di selatan Vietnam. Buat masa ini , hanya karya Phan Huy Le yang bertajuk Hoi An (Faifo) - Past and Present ${ }^{8}$ dan karya Chen Chingho bertajuk Historical Notes on Hoi An (1974) ${ }^{9}$ memberi gambaran umum terhadap komuniti Cina di Hoian. Oleh yang demikian, kajian ini berfokus pada peranan dan sumbangan orang Cina di Hoian pada abad ke-17 hingga abad ke-18.

Kajian ini penting dalam tiga aspek. Yang pertama, setakat ini belum ada kajian khusus tentang peranan dan sumbangan orang Cina di Hoian pada abad ke-17 hingga abad ke-18. Oleh yang demikian, kajian ini berfokus pada peranan dan sumbangan orang Cina di Hoian. Yang kedua, kajian ini mengkaji bagaimana hubungan antara orang Cina dengan kerajaan Nguyen di selatan Vietnam dan hubungan antara orang Cina dengan masyarakat tempatan telah membantu mereka berjaya dalam bidang politik, ekonomi dan sosial di Hoian. Yang ketiga, kajian ini juga membincang usaha orang Cina untuk mengekalkan identiti dan kebudayaan mereka di Hoian. Kajian ini akan membekalkan dimensi baru kepada penulisan sejarah orang Cina di Hoian secara khasnya dan kepada sejarah Vietnam secara amnya.

Dari segi penggunaan sumber, bahan utama sejarah China seperti Hai Wai Ji Shi (Rekod Sejarah Seberang Laut) dan Phu Bien Tap Luc (Rekod Pengamanan Orang Gasar) dirujuk. Bahan-bahan Vietnam yang telah diterbitkan seperti Su Hoc (Pengajian Sejarah) juga merupakan bahan rujukan.

\section{Faktor Penghijrahan Orang Cina ke Hoian, Vietnam}

Terdapat beberapa faktor yang mendorong orang Cina meninggalkan negara China untuk berhijrah ke Hoian. Pergolakan politik di China dari semasa ke semasa telah mendorong ramai orang Cina mencari perlindungan politik di Hoian terutamanya selepas kejatuhan Dinasti Ming pada tahun 1644. Dasar menyimpan tocang yang diperkenalkan oleh kerajaan Qing pada tahun 1645 telah menyebabkan ramai bekas pegawai dan pengikut setia Dinasti Ming berhijrah ke Hoian. ${ }^{10}$ Mereka ini merupakan antara kumpulan yang paling awal menjadi pelarian politik. ${ }^{11}$

Negara China yang sering dilanda masalah kebuluran yang teruk telah memaksa orang Cina mencari tempat yang lebih sesuai sebagai tempat tinggal. Oleh yang demikian, Hoian dipandang sebagai sebuah tempat yang sesuai untuk mendirikan kawasan tempat tinggal memandangkan cara hidup orang Vietnam tidak banyak berbeza dengan cara hidup orang Cina di negara China. ${ }^{12}$

Selain itu, kekurangan tanah pertanian dan bilangan penduduk yang terlalu ramai di selatan China telah menimbulkan masalah kekurangan makanan. Bilangan penduduk yang ramai di China telah memaksa mereka mencari kawasan baru untuk memulakan kehidupan baru. Keadaan bertambah buruk apabila para petani yang miskin sering ditindas oleh tuantuan tanah yang kaya.13 Oleh yang demikian, faktor kemiskinan dan kebuluran juga telah mendorong orang Cina berhijrah ke Hoian. Selain itu, orang Cina berpendapat bahawa adalah lebih mudah untuk mereka mencari rezeki dan menjalankan perdagangan di Vietnam berbanding dengan negara China yang perlu membayar cukai yang tinggi serta polisi yang ketat terhadap aktiviti perdagangan. ${ }^{14}$

Faktor agama juga mendorong penghijrahan orang Cina ke Hoian yang juga dikenali sebagai Faifo. Selepas beberapa sekatan dikenakan pada agama Katholik di China pada abad ke-16, ramai penganut Katholik Cina melarikan diri ke Hoian untuk mengelakkan diri daripada menjadi dipaksa keluar daripada agama Katholik kerana kerajaan China berpendapat bahawa agama Katholik bercanggah dengan kepercayaan tradisional Cina 
kerana penganut Katholik dilarang menyembah nenek-moyang mereka. Beberapa peraturan telah diperkenalkan oleh kerajaan China seperti penganut Katholik wajib menghafal peraturan kampung, mendaftar semua orang asing, mengawal pergerakan penduduk dan merampas pangkat sesiapa yang memberi perlindungan kepada mubaligh Katholik atau penganut Katholik. Malah para mubaligh Katholik di wilayah Fujian turut dipenjarakan sebelum diusir keluar ke Macau sekitar tahun 1630-an. ${ }^{15}$

Selain itu, wabak penyakit yang berleluasa dan malapetaka yang sering kali berlaku di selatan China telah menyebabkan bilangan orang yang mati meningkat. Hal sedemikian telah mendorong penduduk di sini terpaksa mencari punca rezeki di tempat lain. ${ }^{16}$ Maka, Hoian dilihat sebagai satu tempat yang sesuai untuk memulakan kehidupan baru bagi orang Cina.

Pada tahun 1632, pemerintah Nguyen di selatan Vietnam telah memperkenalkan sistem pengambilan pegawai melalui peperiksaan. Dasar ini telah menarik ramai sarjana Cina dari utara Vietnam berhijrah ke Hoian kerana mereka sudah bosan dengan peperangan demi peperangan di utara Vietnam. Terdapat juga orang Cina di utara Vietnam berhijrah ke selatan Vietnam untuk mencari kawasan pertanian yang lebih subur dan luas. ${ }^{17}$

\section{Komuniti Cina di Hoian}

Sejak Nguyen Hoang dilantik sebagai gabenor di Thuan Hoa pada tahun 1558, Hoian dibangunkan sebagai kawasan yang maju. Pada penghujung abad ke-16 hingga awal abad ke-17, Hoian telah menjadi pusat perdagangan antarabangsa yang terkenal. ${ }^{18}$ Hal ini dicatat dalam buku Hai Wai Ji Shi oleh Da Shan. Didapati ramai pedagang Cina Hokkien dari wilayah Fujian, China berniaga di Thuan Hoa dan Hoian. Di Hoian, Jalan Tang Besar (Great Tang Street yang panjangnya tiga hingga empat li (1.5-2.0 kilometer) merupakan tempat berkumpulnya pedagang Cina Hokkien. Perkataan Tang di sini merujuk orang Cina iaitu Tang Ren. Penduduk yang tinggal di sepanjang jalan ini semuanya terdiri daripada pedagang Cina yang berasal dari wilayah Fujian. Mereka memakai pakaian Dinasti Ming. Ini menunjukkan bahawa orang Cina di Hoian masih mengekalkan identiti mereka sebagai orang Minh Huong (orang Cina Dinasti Ming). ${ }^{19}$

Walaupun kerajaan Dinasti Ming dan Nan Ming (南明) ${ }^{20}$ telah digulingkan oleh kerajaan Qing pada tahun 1644 dan tahun 1661, para pemerintah Nguyen tetap menganggap China sebagai Da Ming (Great Ming). ${ }^{21}$ Hal ini menunjukkan betapa kerajaan Ming dipandang tinggi oleh kerajaan Nguyen di selatan Vietnam.

Pedagang Cina yang tinggal di Hoian mempunyai ketuanya yang digelar gabenor dan mereka hidup berpandukan undang-undang di China. Menurut seorang mubaligh Kristian Itali bernama Christoforo Borri yang pernah tinggal di Cochinchina atau selatan Vietnam (1618-1621) telah menulis tentang Hoian seperti berikut, "The city is called Faifo: it is a fairly large one as one part belongs to the Chinese another to the Japanese; they live separately, each having their own governor, the Chinese living according to the laws of China, the Japanese according to those of Japan." 22

Pada awal abad ke-17, penduduk Cina di Hoian boleh dibahagikan kepada tiga kategori. Kategori pertama adalah terdiri daripada pedagang Cina yang terpaksa tinggal di Hoian sehingga tahun berikutnya untuk menguruskan hal perdagangan mereka yang belum diselesaikan ataupun mereka terlepas daripada monsun barat daya yang biasanya bermula pada bulan Jun dan Julai setiap tahun.

Sementara kategori kedua ialah orang Cina yang secara sukarela ingin tinggal tetap ataupun separuh tetap di Hoian. Kebanyakan daripada orang Cina ini adalah pemilik jong, ejen bagi syarikat jong ataupun komprador. Tujuan mereka tinggal di Hoian adalah untuk menghabiskan stok yang ditinggalkan oleh syarikat jong ataupun membuat urusan pembelian barang-barang keluaran tempatan seperti sutera mentah, gula, lada, kelembak, 
sarang burung, kayu sapan, kulit ikan yu dan sebagainya. Penduduk Cina yang tinggal tetap di Hoian menjadi wakil perdagangan di Hoian merupakan satu keperluan pada waktu itu memandangkan bilangan jong Cina yang datang dari China ke Hoian adalah banyak dan sangat kerap. Tambahan pula, ia juga merupakan satu kaedah untuk mengembangkan perdagangan mereka di Hoian. Hal ini telah menunjukkan kebijaksanaan orang Cina dalam perdagangan.

Kategori ketiga pula merujuk orang Cina yang terdiri daripada pemilik hotel, restoran, pekedai runcit, pekedai ubat, tukang jahit dan sebagainya di mana kebanyakan pelanggannya terdiri daripada orang Cina. Orang Cina kategori ketiga datang ke Hoian lebih lewat berbanding dengan orang Cina kategori pertama dan kategori kedua.

Selain daripada tiga kategori orang Cina di Hoian, terdapat juga golongan Cina yang terdiri daripada peneroka, pelarian, pengembara, sami Buddha, tukang tilik dan penjual jamu. Selain itu, juga terdapat orang Cina berketurunan Cina-Vietnam. ${ }^{23}$ Dengan kehadiran orang Cina yang ramai di Hoian, maka terbentuk komuniti Cina di sini.

Pada peringkat awal, penduduk Cina di Hoian dikenali sebagai Thuong Co (pedagang) yang sering kali berulang alik dari China ke Hoian untuk tujuan perdagangan atau Kieu-ngu (penduduk Cina seberang laut) yang tinggal di Hoian untuk berdagang kerana pergolakan politik di China. ${ }^{24}$ Kesemua ini merupakan gambaran am tentang penduduk Cina di Hoian sebelum kejatuhan Dinasti Ming.

Pada tahun 1642, jumlah pedagang Cina seberang laut yang tinggal di Hoian adalah antara 4,000 hingga 5,000 orang. Namun, bilangan orang Cina yang tinggal di Hoian telah meningkat kepada 6,000 orang pada tahun 1744 berdasarkan laporan yang dibuat oleh seorang orang Barat pada tahun tersebut iaitu, "Hoi Pho (Faifo) is the most prosperous spot of commerce throughout Cochinchina. Usually there are about 6,000 Chinese living in this town. They are all wealthy merchants married to local women, and pay taxes to the king". ${ }^{25}$

Jumlah orang Cina yang tinggal di Hoian meningkat kepada 10,000 orang pada tahun 1750. Mereka bekerja sebagai peniaga kecil, buruh yang bekerja di jong pemerintah Nguyen dan pedagang kaya yang mempunyai hubungan perdagangan antarabangsa yang luas. ${ }^{26}$ Menurut laporan Cochinchina pada tahun 1783, "There are only traders residing in the town of "Hue-Hane" (Faifo). In 1750, there were 10,000 married and tax-paying Chinese". 27

Orang Cina di Hoian dibahagikan kepada lima suku (bang) berdasarkan tempat asal mereka di China iaitu Guangdong, Chaozhou, Fujian, Hainan dan Jianing. Menurut Dai Nam Nhat Thong Chi, kawasan petempatan orang Cina di Hoian seperti berikut:

The port city of Hoi an is located on the banks of the big river, to the south of the village of Hoi an and Minh Huong: its brick-covered houses spread out over two dam. Chinese residents from five congregations (according to their provinces of origin: Guangdong, Chaozhou, Fujian, Hainan and Jianing), which trade in Chinese goods, have their common house, market, meeting hall where merchants gather. To the South the Tra Nhieu lake shelters ships having come from the north and the south; it is an important urban centre. ${ }^{28}$

Maka wujudnya kampung Minh Huong yang didirikan oleh orang Cina di Hoian. Pada akhir Dinasti Ming pada abad ke-17, peperangan serta pergolakan politik di China telah menyebabkan ramai pegawai Cina Dinasti Ming dan pelarian Cina melarikan diri ke Hoian. Kedatangan imigran Cina yang ramai ini telah menimbulkan isu penempatan mereka di Hoian memandangkan kemudahan yang terhad di tempat penginapan orang Cina yang sedia ada tidak mampu menampung pertambahan imigran Cina yang bertambah secara tiba-tiba. Tambahan pula golongan imigran Cina ini berbeza dengan penduduk Cina yang tinggal di Jalan Tang Besar. Mereka bukan golongan pedagang tetapi berhasrat untuk tinggal tetap di Hoian. Dalam keadaan ini, maka wujudnya Minh Huong Xa 明乡社 iaitu 
kampung Minh Huong atau kampung orang Cina Dinasti Ming di Hoian. ${ }^{29}$ Kampung Minh Huong wujud lebih kurang dari tahun 1645 hingga tahun 1653.30

Menurut Chen Chingho, istilah Minh Huong (明香) merujuk keturunan Cina-Vietnam yang berkongsi hidup di kampung Minh Huong. ${ }^{31}$ Sementara A. Schreiner berpendapat bahawa Minh Huong bermaksud orang yang mengekalkan taat setia terhadap Dinasti Ming. Ia juga merujuk keturunan hasil perkahwinan antara wanita Vietnam dengan lelaki Cina Dinasti Ming yang mencari perlindungan politik di Cochinchina pada penghujung abad ke17. Menurut A. Schreiner, Minh Huong ialah, "the people maintaining the "Huong Hoa" 香火 (cult) of the Ming dynasty", and that it also indicated "the metis born by the marriage between the Vietnamese women and Ming people who took refuge in Cochinchina in the $17^{\text {th }}$ century". 32

Manakala menurut Nguyen Cam Thuy, istilah Minh Huong (明香) yang terdiri daripada dua perkataan mempunyai maksud tersendiri. Perkataan Minh bermaksud Dinasti Ming. Sementara Huong bermaksud harum. Maksud keseluruhannya ialah bau harum daripada Dinasti Ming. Sementara maksud tersirat Minh Huong (明乡) ialah kampung halaman orang Cina Dinasti Ming. ${ }^{33}$

Berdasarkan inskripsi yang tercatat pada tugu peringatan batu yang berada di Minh Huong Tuy Tien Duong kampung Minh Huong pada abad ke-18 di Hoian, perkataan Minh 明 digunakan untuk menamakan kampung Minh Huong untuk memperingati Dinasti Ming, China. ${ }^{34}$ Kewujudan komuniti Minh Huong di Hoian berkait rapat dengan peristiwa penentangan orang Minh Huong terhadap kerajaan Qing di China. ${ }^{35}$

Orang Minh Huong berkhidmat kepada kerajaan Nguyen di selatan Vietnam dan menerima Hoian sebagai kampung halaman kedua. Mereka masih mengekalkan adat dan kebudayaan orang Cina. Mereka dilarang mengamalkan adat resam Dinasti Qing dalam kehidupan mereka. ${ }^{36}$ Keturunan orang Minh Huong dilayan sama seperti orang Vietnam yang mempunyai kebebasan dalam semua aspek. Mereka juga mempunyai kedudukan yang tinggi dalam istana kerajaan Nguyen di selatan Vietnam. ${ }^{37}$

\section{Peranan dan Sumbangan Orang Cina dalam Bidang Politik}

Orang Cina di Hoian cuba mengekalkan hubungan yang baik dengan pemerintah Nguyen agar mereka dapat hidup aman damai di Hoian. Bagi imigran Cina, mereka memandang Hoian sebagai kampung halaman kedua selain China.

Kebanyakan orang Cina yang berhijrah ke Hoian pada abad ke-17 merupakan bekas pegawai istana dan tentera Dinasti Ming, China. Hubungan baik yang dijalin antara orang Cina dengan kerajaan Nguyen telah mendorong pemerintah Nguyen melantik orang Cina yang berpengalaman dalam pentadbiran untuk memegang jawatan dalam bidang politik. Hal ini menunjukkan amanah dan kepercayaan yang diberikan oleh para pemerintah Nguyen kepada orang Cina yang berkelayakan.

Selain itu, kerajaan Nguyen menganggap bekas tentera Dinasti Ming sebagai sumber tenaga tentera yang boleh membantu kerajaan selatan Vietnam untuk menentang kerajaan Trinh di utara Vietnam serta meluaskan tanah jajahannya ke selatan Vietnam.

Persoalan di sini ialah mengapakah kerajaan Nguyen menerima imigran Cina dengan tangan terbuka ? Hal ini mempunyai kaitan dengan asal usul pemerintah Nguyen yang berketurunan Cina. Penulisan Qing Chao Wen Xian Tong Ka menyatakan bahawa raja Guangnan Guo (Jiaonan) adalah orang Cina yang mempunyai nama keluarga Ruan (Nguyen). Manakala Yue Nan Ji Lue yang dikarang oleh keturunan Nguyen menyatakan bahawa keturunan mereka adalah orang Hokkien dari wilayah Fujian. Sementara Sui Chu Tang Wen Ji mencatat bahawa ketuanya bernama Ruan (Nguyen), keturunan mereka adalah berasal dari wilayah Guangzhou.

Berdasarkan maklumat di atas, dapat dirumuskan bahawa nenek moyang Nguyen adalah orang Hokkien atau orang Kantonis. Da Shan juga menulis surat kepada pemerintah 
Nguyen Phuc Chu menyatakan bahawa berdasarkan sepuluh perkataan yang dicatat pada makam nenek-moyang Nguyen iaitu “Xi Ri Zhong Hua Seng Jin Zhao Nan Guo” 昔日中华僧今 朝南国 yang bermaksud “nenek moyang saya adalah orang Cina dan tuan kepada negara selatan pada hari ini". ${ }^{38}$ Oleh yang demikian boleh disimpulkan bahawa pengasas kerajaan Nguyen di selatan Vietnam adalah orang Cina. Maka adalah tidak hairan mengapa para pemerintah Nguyen di selatan Vietnam menyambut kedatangan imigran Cina yang berhijrah ke Hoian selepas kejatuhan kerajaan Dinasti Ming pada tahun 1644.

Kebijaksanaan pemerintah Nguyen melantik orang Cina yang berpengalaman untuk memegang jawatan dalam pentadbiran telah memperkukuh sistem pentadbiran kerajaan Nguyen kerana bekas pegawai Dinasti Ming memberi taat setia sepenuhnya kepada kerajaan Nguyen untuk memajukan selatan Vietnam. Orang Cina juga telah diberi beberapa jawatan dalam pentadbiran kerajaan Nguyen. Misalnya Liu Qing yang memegang jawatan Cai Phu yang bertanggungjawab menguruskan perdagangan asing. ${ }^{39}$ Khong Thien Nhu pula dilantik sebagai Cai Phu Tau untuk menguruskn jong-jong perdagangan negara asing, menyelia tempat tinggal orang Cina dan pedagang Cina yang baru sampai di Hoian. Manakala Chau Ky Son pernah berkhidmat sebagai Noi Vien yang boleh dianggap sebagai penasihat ekonomi dan kewangan kepada istana Nguyen. Begitu juga Tay Cong Quan juga pernah dilantik sebagai Noi Vien pada zaman pemerintahan Nguyen Phuc Chu (1691-1725) di Hoian. ${ }^{40}$ Perlantikan ini telah menunjukkan bahawa pengalaman pentadbiran yang ada pada bekas pegawai Dinasti Ming telah digunakan sebaiknya oleh pemerintah Nguyen bagi mengukuh dan melicinkan pentadbiran kerajaan selatan Vietnam.

Pada tahun 1702, pemerintah Nguyen Phuc Chu (1691-1725) menghantar dua orang Cina iaitu Huang Chen dan Xing Che sebagai utusan ke Guang Dong, China untuk meminta istana Qing memberi pengiktirafan rasmi kepada kerajaan Nguyen. ${ }^{41}$ Pengiktirafan daripada Istana Qing telah memperkukuh kerajaan Nguyen di selatan Vietnam. Hal ini membuktikan orang Cina memainkan peranan penting dalam politik selatan Vietnam.

Orang Cina juga sering kali terlibat dalam konflik di antara pemerintah Nguyen di selatan Vietnam dengan pemerintah Trinh di utara Vietnam. Semasa pemerintahan Nguyen Phuc Chu (1691-1725), beliau merancang meluaskan kuasa tentera ke utara Vietnam. Maka pada tahun 1716, beliau telah menghantar dua orang pedagang Cina dari wilayah Fujian yang bernama Ping dan Gui ke Bac Ha (utara Vietnam) secara rahsia untuk mengumpul maklumat keadaan tentera dan penduduk utara Vietnam. Laporan daripada Ping dan Gui adalah kerajaan Nguyen harus membatalkan rancangan perluasan kuasa ke utara Vietnam kerana tidak akan mendapat sebarang faedah di Bac Ha. ${ }^{42} \mathrm{Hal}$ ini menunjukkan kebijaksanaan pemerintah Nguyen Phuc Chu melantik dua orang pedagang Cina untuk menjalankan misi tersebut agar tidak menimbulkan syak wasangka kerajaan utara Vietnam kerana kedua-dua orang Cina tersebut masuk ke utara Vietnam dengan menggunakan identiti sebagai pedagang. Hal ini membuktikan kepentingan orang Cina dalam pentadbiran kerajaan Nguyen.

\section{Peranan dan Sumbangan Orang Cina dalam Bidang Ekonomi}

Peranan dan sumbangan orang Cina dalam bidang ekonomi di Hoian paling jelas berbanding dengan politik dan sosial. Kebanyakan orang Cina yang tinggal di Hoian terdiri daripada pedagang. Kehandalan dan bakat orang Cina dalam perdagangan telah memajukan ekonomi di Hoian. Sehubungan itu, orang Cina di Hoian telah dilantik oleh pemerintah Nguyen untuk memegang jawatan penting dalam bidang perdagangan. Aktiviti ekonomi orang Cina di Hoian dapat digambarkan melalui penerokaan kawasan baru dan kegiatan perdagangan terutamanya pada abad ke-17 dan abad ke-18.

Menurut P. Poivre, imigran Cina di Hoian juga perlu membayar ufti kepada raja.43 Cukai yang dikutip oleh pemerintah Nguyen daripada pedagang Cina merupakan sumber 
kewangan yang sangat lumayan kepada kerajaan Nguyen untuk membeli alat senjata yang moden untuk menentang kerajaan Trinh di utara Vietnam dan meluaskan tanah jajahannya ke selatan Vietnam.

Orang Cina yang berkaliber telah dilantik untuk memegang jawatan dalam pentadbiran untuk menguruskan perdagangan pada zaman pemerintahan Nguyen di selatan Vietnam. Misalnya Liu Qing dilantik sebagai Cai Phu yang bertanggungjawab untuk menguruskan perdagangan asing. ${ }^{44}$

Sementara Khong Thien Nhu yang merupakan bekas pegawai Dinasti Ming di China dilantik sebagai pegawai Cai Phu Tau 该府艚 untuk mengawal jong perdagangan negara asing, menyelia tempat tinggal orang Cina dan pedagang Cina yang baru sampai di Hoian. Khong Thien Nhu juga menjaga kebajikan orang Cina dan orang Minh Huong di Hoian. Apabila Khong Thien Nhu meninggal dunia pada tahun 1695, pemerintah Nguyen Phuc Chu (1691-1725) mendirikan tokong Khong Thien Nhu untuk memperingati jasa beliau. ${ }^{45}$

Menurut Phu Bien Tap Luc (Vol. 4), pegawai yang bertanggungjawab terhadap perdagangan seberang laut semasa pemerintahan Nguyen dikenali sebagai Tau Bo 艚部atau Tau Ty 艚司 di mana pegawai kanannya terdiri daripada seorang Cai Tau, seorang Tri Tau, dua orang Cai Ba Tau, dua orang Cai Phu Tau, dua orang Ky Luc Tau dan dua orang Thu Tau. ${ }^{46}$ Menurut buku An-nan Kung-yi Chi-shih 安南供役记事 yang dikarang oleh Chu Shun Shuei, jawatan Cai Tau bertanggungjawab menyelia penduduk Cina dan mengawal hal perkapalan. Biasanya, jawatan Cai Phu Tau atau Ky Luc Tau dipegang oleh orang Minh Huong atau pedagang Cina yang tinggal di Hoian. Pada tahun 1657, orang Cina Hokkien dilantik sebagai Cai Phu di Hoian. ${ }^{47}$

Seorang lagi bekas pegawai Dinasti Ming iaitu Chau Lao Gia (Chau Ky Son) pernah berkhidmat kepada kerajaan Nguyen sebagai Cai Phu Tau dengan gelaran khas "Noi Vien" 内院. Gelaran "Noi Vien" dianugerahkan oleh pemerintah Nguyen kepada penduduk Cina yang berpengaruh dalam ekonomi atau kewangan. Oleh yang demikian, jawatan "Noi Vien" boleh dianggap sebagai penasihat atau kaunselor kepada istana Nguyen. ${ }^{48}$ Perlantikan Chau Ky Son sebagai Cai Phu Tau membuktikan bahawa orang Minh Huong yang berkaliber dan berpengalaman dalam bidang pentadbiran telah dilantik sebagai pegawai tinggi di Hoian. Ia juga menunjukkan sikap terbuka dan kebijaksanaan pemerintah Nguyen untuk melantik orang Cina yang berkaliber untuk membantu beliau mentadbir Hoian. Bagi orang Minh Huong di Hoian, walaupun mereka menetap di rantau orang, mereka tetap memberi taat setia yang sepenuhnya kepada pemerintah Nguyen. Ketaatan orang Minh Huong kepada pemerintah Nguyen di selatan Vietnam boleh dilihat daripada dua sudut. Yang pertama, mereka enggan berkhidmat kepada kerajaan Qing di China. Yang Kedua, mereka ingin membalas jasa pemerintah Nguyen yang sanggup menerima mereka untuk tinggal di Hoian.

Sementara Ngo Dung Minh yang merupakan bekas pegawai Dinasti Ming (ahli Luc Tinh ${ }^{49}$ bekerja di jabatan Cai Phu Tau dengan gelaran "Marquis of Minh Duc". ${ }^{50}$ Manakala Tay Cong Quan yang berasal dari keluarga Tay Quoc Tuong (ahli Thap Lao) ${ }^{51}$ dilantik sebagai Noi Vien pada zaman pemerintahan Nguyen Phuc Chu (1691-1725) di Hoian.52 Perlantikan bekas pegawai Dinasti Ming sebagai pegawai tinggi telah mengukuhkan pentadbiran kerajaan Nguyen di selatan Vietnam.

Menurut Purcell, Hoian merupakan pusat perdagangan yang pertama yang didirikan oleh imigran Cina. ${ }^{53}$ Ini adalah kerana pemerintah Nguyen Hoang (1558-1613) yang mengasaskan Dinasti Nguyen di Thuan Hoa telah membenarkan orang Cina menjalankan perdagangan dengan pedagang asing di Hoian. Justeru itu, pada penghujung abad ke-16 hingga awal abad ke-17, Hoian telah menjadi pusat perdagangan antarabangsa yang terkenal. 54

Selain menguruskan perdagangan sendiri, pedagang Cina di Hoian juga menjadi orang tengah atau ejen antara kerajaan Nguyen dengan Syarikat Belanda. Misalnya pada 10 
Mei 1636, sebuah jong Cina sampai di Batavia dengan membawa surat rasmi Nguyen Phuc Lan (Chua Thuong, 1635-1648) untuk ditujukan kepada gabenor Belanda yang berada di Batavia, Indonesia. ${ }^{55} \mathrm{Hal}$ ini telah membuktikan bahawa pedagang Cina di Hoian telah memainkan peranan yang penting dalam membantu kerajaan Nguyen Phuc Lan untuk menguruskan perdagangan di seberang laut.

Pada tahun 1637, memandangkan tiada kapal Belanda belayar ke Jepun pada tahun tersebut, maka ketua pedagang kilang Belanda di Hoian yang bernama Cornelis Caesar telah mengamanahkan 357 pikul gula merah yang telah dipesan oleh kilang Belanda dari Nagasaki, Jepun kepada jong pedagang Cina di Hoian yang bernama Simsingh dan 637 pikul gula merah kepada jong pedagang Cina yang bernama Bij Quan yang belayar ke Nagasaki. 56 Tindakan Cornelis Caesar tersebut telah membuktikan bahawa sikap kebolehpercayaan yang selama ini diamalkan oleh pedagang Cina di Hoian telah menambat hati Cornelis Caesar untuk memberi tugas tersebut kepada dua orang pedagang Cina. Sebenarnya sikap kebolehpercayaan yang ada pada para pedagang Cina merupakan kunci kejayaan mereka dalam menguasai kegiatan ekonomi di Hoian.

Selain itu, epitaf yang terdapat pada makam dua orang adik-beradik yang bernama Nguy Nguyen Du dan Nguy Chi Phuong di Tra Nhieu Nam, Hoian pada tahun 1696 telah membuktikan bahawa terdapatnya penduduk Foochow di Hoian. Mereka berasal dari Futsing di kawasan Foochow, wilayah Fujian. ${ }^{57}$ Khong Thien Nghi yang tinggal di Hoian merupakan kapten jong Cina yang mengetuai lebih kurang 60 orang pedagang pada abad ke-17.58 Sementara Hua Trinh Quan, Hua Thuong Quan dan Hua Man Quan merupakan pemilik jong atau separa pemilik jong pada akhir 1680-an.

Orang Cina juga mewujudkan hubungan yang erat dengan orang Vietnam. Kecekapan kaum wanita tempatan dalam perniagaan telah menarik perhatian pedagang Cina lelaki untuk berkahwin dengan mereka untuk memudahkan segala urusan perdagangan di Hoian. ${ }^{59}$ Misalnya pedagang Cina yang bernama Nguy Chi Diem yang tinggal di Hoian (1654 - 1672) berkahwin dengan wanita Vietnam Vi Thi Nghi berjaya mengumpul kekayaan di Hoian melalui perdagangan Quang Nam dengan Jepun pada abad ke-17. ${ }^{6}$ Perkahwinan seperti ini didorong oleh faktor keperluan perdagangan dan kebudayaan yang hampir sama antara orang Cina dengan orang Vietnam. Hal ini menunjukkan bahawa pedagang Cina bijak menggunakan segala strategi yang boleh membantu mereka berjaya dalam perdagangan. Menurut Da Shan:

Hoi An is a big sea port, a meeting place for merchants from many countries. The main road (Dai duong cai), 3 to 4 leagues long runs along the bank of the river: it is bordered on both sides by closely built houses inhabited by people who came from Fujian. They wear the clothing of the previous dynasty (Ming). Most of the women take care of the commercial dealings. Chinese residents generally married many local women in order to facilitate their negotiations. ${ }^{61}$

Perjalanan dari Guangzhou ke Thuan Hoa dan Quang Nam hanya memerlukan enam hari melalui jalan laut. ${ }^{62}$ Perjalanan yang pendek ini telah menggalakkan kegiatan perdagangan antara pedagang China dengan pedagang Cina di Hoian. Tambahan pula, penghapusan "Li Chieh Ling" 63 pada tahun 1685 yang membenarkan semula perdagangan di seberang laut telah memajukan ekonomi di Hoian.

Oleh yang demikian, selepas suku pertama abad ke-18, jong-jong Cina yang berdagang di Hoian telah bertambah secara berterusan sehingga memperlihat zaman keemasan perdagangan di Hoian pada tahun 1750. Menurut J. Koffler yang telah tinggal di Quang Nam (1740 - 1755), "Every year, there are about 80 Chinese junks coming to trade from various ports. Considering that the vessels keep coming also from Macao, Batavia and France, you may understand the prosperity of commerce in this country". .4 
Pertambahan kapal pedagang Cina di Hoian menguntungkan orang Cina di sini kerana mereka menguasai kapal-kapal pedagang Cina dari Jepun, Quangzhou, Siam, Khmer, Manila dan Batavia yang datang bersinggah di Hoian. Kegiatan ekonomi di Hoian terjejas teruk apabila berlakunya pemberontakan Tay Son pada tahun 1771 di Binh Dinh yang merupakan sebahagian daripada wilayah kerajaan Nguyen. ${ }^{65}$ Jumlah perdagangan di Hoian merosot dari tahun 1771 hingga tahun 1773 seperti jadual berikut:

Jadual 1: Jumlah Perdagangan di Hoian, 1771-177366

\begin{tabular}{|c|c|}
\hline Tahun & Jumlah Perdagangan di Hoian \\
\hline 1771 & 30,800 quan \\
\hline 1772 & 14,300 quan \\
\hline 1773 & 3,200 quan \\
\hline
\end{tabular}

Maka dapat dirumuskan bahawa perang saudara yang berlaku di selatan Vietnam telah memberi tamparan yang teruk kepada perdagangan di Hoian.

Kejayaan orang Cina dalam bidang ekonomi di Hoian mempunyai kaitan dengan sifat amanah yang diamalkan oleh orang Cina. Amanah merupakan elemen yang amat penting dalam kehidupan orang Cina terutamanya dalam bidang perniagaan. Orang Vietnam percaya bahawa berniaga dengan orang Cina adalah selamat dan tidak akan ditipu ataupun dikhianati oleh mereka. ${ }^{67}$ Sikap kebolehpercayaan yang ada pada orang Cina telah membantu mereka membina empayar ekonomi yang kukuh di Hoian.

\section{Peranan dan Sumbangan Orang Cina dalam Bidang Sosial}

Orang Cina yang tinggal di Hoian tidak pernah lupa tentang identiti dan kebudayaan Cina. Mereka masih mengekalkan kebudayaan dan identiti mereka sebagai orang Cina di Hoian. Malah orang Cina cuba mengembangkan kebudayaan Cina di Hoian.

Ke mana orang Cina pergi, kebudayaan Cina akan dibawa ke sana. ${ }^{68}$ Ciri-ciri kehidupan, adat istiadat dan kebudayaan komuniti Cina di Hoian dapat dilihat dengan jelas pada abad ke-17. Negara China dianggap sebagai pusat dunia sementara orang China dikenali sebagai "Anak Langit" (Con Troi). Oleh yang demikian, orang Cina di Hoian sentiasa berasa bangga kerana mempunyai tamadun yang ulung dan bersemangat tinggi untuk memelihara identiti mereka. ${ }^{69}$

Tulisan Cina merupakan warisan kebudayaan Cina. Setiap komuniti Cina memberi keutamaan dalam hal pengajaran dan pembelajaran tulisan Cina. Tulisan Cina telah diperkembangkan melalui kesusasteraan, sejarah dan kepercayaan. Orang Cina juga sentiasa mementingkan nasihat yang diberikan oleh ahli komuniti untuk memelihara kebudayaan Cina. Kerajinan, kesabaran dan amanah yang ada pada orang Cina telah menjadikan komuniti Cina di Hoian sebagai sebuah komuniti yang kuat.

Di Hoian, orang Cina mendirikan hoi quan (persatuan), tokong Cina, pasar, hospital, sekolah Cina dan kubur Cina. Pembinaan hoi quan dan tokong Buddha merupakan monumen dan bukti yang kukuh wujudnya kebudayaan Cina di Hoian. Semua ini berkait rapat dengan perniagaan dan kerjaya orang Cina di Hoian agar dewa-dewi memberi perlindungan terhadap kerjaya mereka. ${ }^{70} \mathrm{Wujudnya}$ asimilasi menyaling dalam agama orang Cina di Hoian iaitu setiap tokong Cina atau hoi quan yang didirikan memuja dewadewi yang berbeza.

Tokong Quan Thanh yang dipercayai dibina pada tahun 1653 oleh orang Minh Huong merupakan tokong yang terawal di Hoian. Tokong ini memuja Kuan Yu. Sementara tokong Quan Am yang dibina di belakang tokong Quan Thanh juga dipercayai dibina pada tahun 1653 oleh orang Minh Huong. ${ }^{11}$ Kedua-dua tokong ini memainkan peranan penting 
dalam sosial dan kehidupan penduduk Cina di Hoian. Berdasarkan catatan Da Shan yang tinggal di Di Da Tu (temple of Di Da) di Hoian pada tahun 1695, "There is Quan Phu Tu Mieu (Quan Thanh Temple) on the right of Di Da Tu (where I was lodging). The Mieu (shrine) serving as Hoi Quan (the Assembly Hall) of the Min people (Hokien), was the object of the most prosperous religious rites. ${ }^{72}$

Sumbangan orang Cina dalam bidang sosial dapat dilihat melalui tiga orang pedagang dan dermawan Cina iaitu Tay Quoc Tuong, Ngo Dinh Khoan dan Truong Hoang Co yang sentiasa menjaga kebajikan komuniti Minh Huong dengan membantu golongan yang miskin. Malah pada tahun 1753, mereka menderma duit kepada Tokong Quan Thanh untuk membuat kerja pembaik pulihkan. ${ }^{73}$

Tokong Cina lain yang dibina di Hoian pada abad ke-17 ialah Cam Ha Hai Binh Nhi Cung iaitu tokong Cam Ha dan tokong Hai Binh. Penduduk Cina memuja dewa Bao Sinh Dai De (His Majesty the Protector of Life) dan 36 orang Jeneral di tokong Cam Ha. Sementara di tokong Hai Binh, penduduk Cina memuja dewi Thien Hau (Queen of Heaven) dan Sinh Thai Nhi Tien Nuong (Twelve fairly Protector of Births). Selain itu, Van Tho Dinh (Pavillion of Longevity) dan Quang Yen Tu juga merupakan tokong Cina yang dibina pada abad ke-17.

Selain tokong, terdapat juga hoi quan yang didirikan oleh bang (suku kaum Cina) di Hoian pada abad ke-17. Hoi quan ditadbir oleh ahli jawatankuasa bang. Setiap bang mempunyai sekolah, tapak perkuburan, hospital dan tokong sendiri untuk membekalkan kemudahan kepada ahli-ahlinya.

Hoi quan di Hoian mempunyai dua fungsi iaitu sebagai tempat pertemuan antara ahli bang dan sebagai tokong untuk memuja dewa-dewi bang sendiri. Terdapat empat hoi quan di Hoian iaitu Phuc Kien Hoi Quan (Persatuan Fujian), Quang Trieu Hoi Quan (Persatuan Quandong), Trieu Chau Hoi Quan (Persatuan Teichiu) dan Quynh Phu Hoi Quan (Persatuan Hainan) yang dimiliki oleh bang yang berbeza. Sementara Trung Hoa Hoi Quan (Persatuan Trung Hoa) merupakan persatuan yang menggabungkan semua persatuan dialek.

Phuc Kien Hoi Quan dibina pada tahun 1757 oleh seorang pedagang Hokkien yang berasal dari Chuan Chow yang bernama Shih Hung Cheh, merupakan hoi quan yang tertua di Hoian. Phuc Kien Hoi Quan juga dikenali sebagai Thien Hau Mieu (Shrine of the Queen of Heaven). ${ }^{74}$ Hoi quan di Hoian bukan sahaja memberi perkhidmatan kepada orang Cina bahkan memberi perkhidmatan kepada orang tempatan. Semasa Tet (Tahun Baru Cina atau Vietnam), orang Cina dan orang Vietnam pergi ke tokong Cina dan hoi quan (persatuan) untuk memohon restu daripada dewa-dewi agar memberi kebahagiaan dan perlindungan kepada ahli sekeluarga dan komuniti sepanjang tahun. Maka wujudnya pengaruh kebudayaan Cina ke atas orang Vietnam dan berlakunya proses integrasi melalui perkongsian kepercayaan.

Dalam hal perkahwinan, ramai orang Cina tidak ingin berkahwin dengan penduduk peribumi kerana bimbang akan kehilangan identiti mereka sebagai orang Cina. ${ }^{75}$ Walaupun orang Cina telah meninggalkan kampung halaman mereka di China, namun mereka tidak pernah melupakan kebudayaan Cina semasa mereka berada di Hoian. Tokong-tokong dan persatuan Cina telah didirikan sebagai tanda untuk memelihara dan mempertahankan kebudayaan Cina di rantau orang.

\section{Kesimpulan}

Sejak pemerintah Nguyen Hoang menjadi gabenor di Thuan Hoa pada tahun 1558, Hoian telah dimajukan sehingga menjadi sebuah pelabuhan antarabangsa yang maju pada abad ke-17 dan abad ke-18. Kehadiran kapal-kapal dagang asing terutamanya jong-jong Cina yang banyak di pelabuhan Hoian telah menyumbang sumber kewangan yang lumayan kepada kerajaan Nguyen melalui pungutan cukai import dan eksport daripada para pedagang. Sumber kewangan tersebut membolehkan kerajaan Nguyen melengkapkan 
pasukan tenteranya dengan alat senjata yang moden untuk menentang serangan daripada kerajaan Trinh di utara Vietnam.

Kehadiran imigran Cina di Hoian terutamanya pada abad ke-17 dan abad ke-18 telah menukar komposisi masyarakat Hoian. Pengikut setia Dinasti Ming yang bertapak di Hoian telah mendirikan kampung Minh Huong dan menunjukkan taat setia mereka kepada Dinasti Ming. Dasar keterbukaan kerajaan Nguyen di selatan Vietnam telah mendorong ramai orang Cina berhijrah ke Hoian untuk mencari perlindungan dan memulakan lembaran hidup baru di negara baru. Ekoran daripada dasar tersebut, akhirnya terbentuk sebuah komuniti Cina yang besar di Hoian pada abad yang ke-18.

Kehadiran orang Cina di Hoian telah membawa pembaharuan dan pemodenan di Hoian. Perlantikan bekas pegawai Dinasti Ming sebagai pegawai kerajaan Nguyen telah membantu kerajaan Nguyen mewujudkan sistem pentadbiran yang bersistematik dan teratur. Kebijaksanaan orang Cina untuk menguruskan perdagangan telah berjaya meningkatkan ekonomi Hoian dan seterusnya menjadikan Hoian sebagai sebuah pelabuhan antarabangsa yang makmur. Sementara bekas tentera Dinasti Ming telah membantu kerajaan Nguyen untuk meluaskan tanah jajahannya ke selatan Vietnam.

Para pemerintah kerajaan Nguyen iaitu bermula dari Nguyen Hoang (1558-1613), Nguyen Phuc Nguyen (1613-1635), Nguyen Phuc Lan (1635-1648), Nguyen Phuc Tan (16481687), Nguyen Phuc Tran (1687-1691), Nguyen Phuc Chu (1691-1725), Nguyen Phuc Tru (1725-1738), Nguyen Phuc Khoat (1738-1765) sehingga Nguyen Phuc Thuan (1765-1777), semuanya merupakan pemimpin yang berkaliber dan berfikiran terbuka dengan melantik imigran Cina yang berpengalaman dan berkelayakan untuk memegang jawatan penting dalam pentadbiran politik dan ekonomi di Hoian. Hasil daripada tindakan tersebut, akhirnya Hoian berkembang menjadi sebuah bandar pelabuhan yang makmur dan terkenal di peringkat antarabangsa.

\section{Nota}

1 Luong Nhi Ky, The Chinese in Vietnam: A Study of Vietnamese-Chinese Relations with Special Attention to Period 1862-1961, University Microfilms, Inc., 1963, hlm. 2.

2 D.R. SarDesai, Vietnam: The Struggle for National Identity, Boulder: Westview Press, Inc., 1992, hlm. 2.

3 Chau Hai, "Vai Net Ve Su Di Dan Cua Nguoi Hoa Dong Nam A Va Cac To Chuc Cong Dong Xa Hoi Cua Ho" dalam Su Hoc, So II, 1976-1990, Ha Noi: Nha Xuat Ban Dai Hoc Va Trung Hoc Chuyen Nghiep, 1981, hlm. 117 (Chau Hai “Sejarah Imigran Cina Asia Tenggara dan Pertubuhan Kegiatan Sosial Mereka" dalam Pengajian Sejarah, Jil. 2, 1976-1990, Hanoi: Penerbit Universiti dan Sekolah Menengah, 1981).

4 Nguyen Cam Thuy, Dinh Cu Cua Nguoi Hoa Tren Dat Nam Bo, Tu The Ky XVII Den Nam 1945, Ha Noi, Nha Xuat Ban Khoa Hoc Xa Hoi, 2000, hlm. 14 (Nguyen Cam Thuy, Petempatan Orang Cina di Selatan Vietnam dari Abad Ke-17 Hingga Tahun1945, Hanoi : Penerbit Sains Sosial, 2000).

5 Ibid., hlm. 7.

6潘安, 越南南部华人文化考究, 西贡: 西贡解放日报, 2006, hlm. 11 (Phan An, Budaya Orang Cina di Selatan Vietnam. Saigon : Saigon Liberal Press, 2006).

7 Nguyen The Anh, "Hoa Kieu Va Su Dinh Dan Tai Vung Dong Bang Song Cuu Long” dalam Nghien Cuu Hue, Tap Bon, Trung Tam Nghien Cuu Hue, 2002, hlm. 104 (Nhuyen The Anh, "Cina Seberang Laut dan Petempatan di Dataran Mekong" dalam Kajian Hue, Jil. 4, Pusat Penyelidikan Hue, 2002).

8 Phan Huy Le, “Hoi An (Faifo) - Past and Present," dalam Ancient Town of Hoi An, Hanoi: Foreign Language Publishing House, 1991, hlm. 14.

9 Chen Chingho(ed.), Historical Notes on Hoi-An (Faifo), Carbondale: Southern Illinois University Center for Vietnamese Studies, 1974, hlm. 23

10 陈生雪, “清初的社会矛盾”，郑天挺主编，明清史资料，天津市：天津人民出版社，1981，hlm. 19 (Zheng Tian Tin (ed.), Dokumen Sejarah Dinasti Ming dan Dinasti Qing, Tian Jin: Tian Jin Ren Min 
Chu Ban She, 1981) dan Tran Khanh, The Ethnic Chinese and Economic Development in Vietnam, Singapore: Institute of Southeast Asian Studies, 1993, hlm. 15.

11 Joseph Buttinger, The Smaller Dragon: A Political History of Vietnam, New York: Frederick A. Praeger, 1958, hlm. 93.

12 Tran Khanh, The Ethnic Chinese and Economic Development in Vietnam, Singapore: Institute of Southeast Asian Studies, 1993, hlm. 13; Joseph Buttinger, The Smaller Dragon, hlm. 93.

13 潘安, 越南南部华人文化考究, 西贡: 西贡解放日报, 2006, hlm. 11 (Phan An, Budaya Orang Cina di Selatan Vietnam, Saigon: Saigon Liberal Press, 2006).

14 Tran Khanh, The Ethnic Chinese and Economic Development in Vietnam, Singapore: Institute of Southeast Asian Studies, 1993, hlm. 13-14.

15 Nguyen Cam Thuy, Dinh Cu Cua Nguoi Hoa Tren Dat Nam Bo, hlm. 7.

16 潘安, 越南南部华人文化考究, 西贡: 西贡解放日报, 2006, hlm. 11 (Phan An, Budaya Orang Cina di Selatan Vietnam, Saigon: Saigon Liberal Press, 2006).

17 Joseph Buttinger, The Smaller Dragon, hlm. 169.

18 Phan Huy Le, "Hoi An (Faifo) - Past and Present", hlm. 19.

19 大汕, 余思黎点校, 海外级事, 卷四, 北京: 中华书局, 2000, hlm. 80 (Da Shan, Hai Wai Ji Shi (Record of Countries Overseas), Vol.4, Beijing: Beijing Zhong Hua Shu Ju, 2000).

20 Nan Ming merujuk kerajaan yang didirikan oleh pegawai Dinasti Minh di Jiang Nan pada tahun 1644 selepas tentera kerajaan Qing menakluki Hebei(河北) dan Shandong (山东), China. 谢 国 桢, “南明建立的政权为什么会这样的短促”, 郑天挺主编, 明清史资料, 天津市: 天津 人民出版社, 1981, hlm. 35. (Zheng Tian Tin (ed.), Dokumen Sejarah Dinasti Ming dan Dinasti Qing, Tian Jin: Tian Jin Ren Min Chu Ban She, 1981).

21 大汕, 余思黎点校, 海外纪事, 卷二, 北京: 中华书局, 2000, hlm. 46 (Da Shan, Hai Wai Ji Shi (Record of Countries Overseas) Vol.2, Beijing : Beijing Zhong Hua Shu Dian, 2000).

22 Nguyen Dinh Dau, "The Birth and the Historic Evolution of Hoi An" dalam Ancient Town of Hoi An, Hanoi: The Gioi Publishers, 1993, hlm. 118.

23 Chen Chingho A., Historical Notes on Hoi-An (Faifo), Southern Illinois University: Center for Vietnamese Studies, 1974, hlm. 35-36.

$24 \quad$ Ibid., hlm. 36.

$25 \quad$ Ibid., hlm. 18.

26 Nguyen The Anh, "Trade Relations Between Vietnam and the Countries of the Southern Seas in the First Half of the 19 $9^{\text {th }}$ Century" dalam Nguyen the Anh dan Yoshiaki Ishizawa (eds.), Trade and Navigation in Southeast Asia (14th $19^{\text {th }}$ Centuries, Paris: L'Harmmattan, 1999, hlm. 176. Chen Chingho A., Historical Notes on Hoi-An (Faifo), hlm. 18.

28 Nguyen Dinh Dau, "The Birth and the Historic Evolution of Hoi An", hlm. 117-118.

29 Chen Chingho A., Historical Notes on Hoi-An (Faifo), hlm. 36.

30 Nguyen Cam Thuy, Dinh Cu Cua Nguoi Hoa Tren Dat Nam Bo, hlm. 14.

31 Chen Chingho A., Historical Notes on Hoi-An (Faifo), hlm. 36-37.

32 Ibid., hlm. 37.

33 Nguyen Cam Thuy, Dinh Cu Cua Nguoi Hoa Tren Dat Nam Bo, hlm. 8.

34 Chen Chingho A., Historical Notes on Hoi-An (Faifo), hlm. 37.

35 Chau Hai, Cac Nhom Cong Dong Nguoi Hoa O Viet Nam, Viet Nam: Nha Xuat Ban Khoa Hoc Xa Hoi, 1992, hlm.56 (Chau Hai, Kumpulan Orang Cina di Vietnam, Vietnam: Penerbit Sains Sosial, 1992).

36 Nguyen Cam Thuy, Dinh Cu Cua Nguoi Hoa Tren Dat Nam Bo, hlm. 13.

37 Ibid., hlm. 68.

38 大汕, 余思黎点校, 海外纪事, 卷三, 北京: 中华书局, 2000, hlm. 73 (Da Shan, Hai Wai Ji Shi (Record of Countries Overseas), Vol. 3, Beijing: Beijing Zhong Hua Shu Ju, 2000).

39 Yang Baoyun, Contribution a l'histoire de la principaute des Nguyen au Vietnam meridional (1600-1775), Geneve: Editions Olizane, 1992, hlm. 174 (Yang Baoyun, Sumbangan Sejarah Pemerintah Nguyen di Selatan Vietnam (1600-1775), Geneve: Editions Olizane, 1992).

40 Chen Chingho A., Historical Notes on Hoi-An (Faifo), hlm. 47-48, 54.

${ }^{41}$ Yang Baoyun, Contribution a l'histoire de la principaute, hlm. 170-171.

42 Ibid. 
Yang Baoyun, Contribution a l'histoire de la principaute, hlm. 173.

Chen Chingho A., Historical Notes on Hoi-An (Faifo), hlm. 46.

Ibid., hlm. 48.

Phu Bien Tap Luc, Vol. 4 (Rekod Pengamanan Orang Gasar, Jil. 4); Chen Chingho A., Historical Notes on Hoi-An (Faifo), hlm. 47.

Chen Chingho A., Historical Notes on Hoi-An (Faifo), hlm. 47-48.

Ibid., hlm. 46.

Luc Tinh merupakan kumpulan penduduk yang lebih tua dan masyhur di kampung Minh Huong. Mereka biasanya terlibat dalam perdagangan.

Chen Chingho A., Historical Notes on Hoi-An (Faifo), hlm. 49.

Thap Lao merupakan penduduk Kampung Minh Huong yang berkhidmat sebagai pegawai kerajaan.

Chen Chingho A., Historical Notes on Hoi-An (Faifo), hlm. 54.

Victor Purcell, The Chinese in Southeast Asia, London: Oxford University Press, 1965, hlm.183.

Phan Huy Le, "Hoi An (Faifo) - Past and Present", hlm. 19.

Chen Chingho A., Historical Notes on Hoi-An (Faifo), hlm. 21-22.

Ibid., hlm. 23.

Ibid., lm. 50.

Ibid., hlm. 46-47.

大汕, 余思黎点校, 海外级事, 卷四, 北京: 中华书局, 2000, hlm. 80 (Da Shan, Hai Wai Ji Shi (Record of Countries Overseas), Vol. 4, Beijing: Beijing Zhong Hua Shu Ju, 2000).

Chen Chingho A., Historical Notes on Hoi-An (Faifo), hlm. 50.

大汕, 余思黎点校, 海外级事, 卷四, 北京: 中华书局, 2000, hlm. 80; Nguyen Dinh Dau, “The Birth and the Historic Evolution of Hoi An", hlm. 118.

Li Tana and Anthony Reid (eds.), Southern Vietnam under the Nguyen: Document on the Economic History of Cochinchina (Dang Trong), 1602-1777, Singapore: Institute of Southeast Asian Studies, 1995, hlm. 116.

Li Chieh Ling diperkenalkan oleh kerajaan Qing pada tahun 1661 yang mengharamkan pelayaran dan perdagangan seberang laut untuk mengelakkan penduduk China di Asia Tenggara berkomplot dengan golongan penentang Dinasti Ming untuk menentang kerajaan Qing.

Chen Chingho A., Historical Notes on Hoi-An (Faifo), hlm. 26.

Choi Byung Wook, Southern Vietnam under the Region of Minh Mang (1820-1841), Central Polisi and Local Response, Ithaca: Cornell University, 2004, hlm. 20; Nguyen the Anh, Hoa Kieu Va Su Dinh Dan Tai Vung Dong Bang Song Cuu Long, hlm. 104.

Chen Chingho A., Historical Notes on Hoi-An (Faifo), hlm. 27.

Nguyen Cam Thuy, Dinh Cu Cua Nguoi Hoa Tren Dat Nam Bo, hlm. 70.

Ibid., hlm. 47-48.

Ibid., hlm. 68.

Ibid., hlm. 52-53.

Chen Chingho A., Historical Notes on Hoi-An (Faifo), hlm. 59-61.

大汕, 余思黎点校, 海外级事, 卷四, 北京: 中华书局, 2000, hlm. 80; Chen Chingho A., Historical Notes on Hoi-An (Faifo), hlm. 62.

Chen Chingho A., Historical Notes on Hoi-An (Faifo), hlm. 50-51.

Ibid., hlm. 65-66.

Nguyen Cam Thuy, Dinh Cu Cua Nguoi Hoa Tren Dat Nam Bo, hlm. 69. 